\section{Endosonographic Features of a Calcified Mucinous Gastric Carcinoma}

Calcification within gastric adenocarcinoma is an infrequent occurrence $(1-3)$. We report here a 68 -year-old woman with calcified gastric cancer in whom the intramural calcifications were clearly demonstrated by endoscopic ultrasonography (EUS). An upper gastrointestinal endoscopy revealed a large fungating tumor in the lesser curvature of the antrum. Although a plain radiography showed no features of calcification, a computed tomography revealed multiple punctuate calcifications within the stomach wall. By EUS their location in the gastric wall was clearly demonstrated (Figure 1). The resected specimen revealed a mucinous T3-stage adenocarcinoma. Although mucin pools containing signet ring cells and calcifications were present in the deeper layer, the poorly differentiated adenocarcinoma was recognized as a mucosal element (Figure 2). The metastasis to the regional lymph nodes was also confirmed.

To our knowledge, this is the first report of endosonographic demonstration of a calcified gastric carcinoma. With its unique ability to visualize each layer of the stomach wall $(4,5)$, EUS was superior to other imaging techniques, such as computed tomography, and we could easily diagnose the location of the calcifications as well as the depth of tumor invasion.

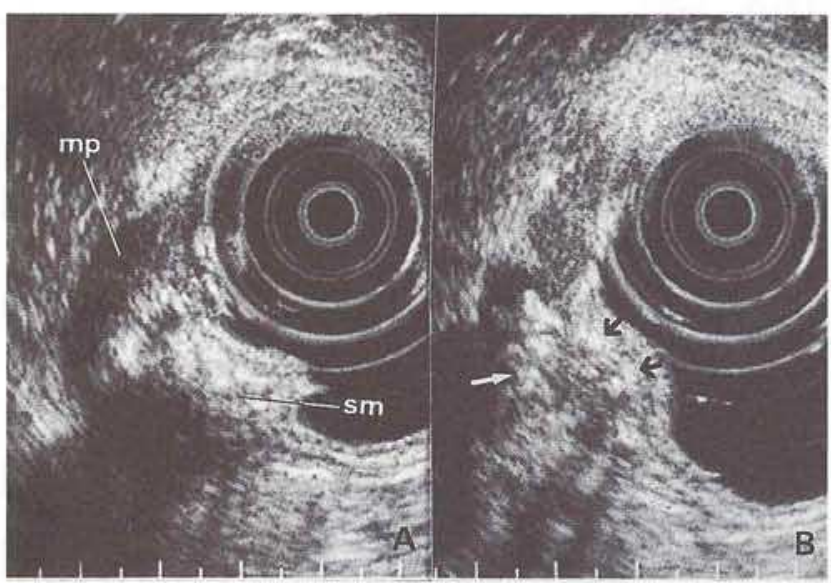

Figure 1: EUS image of the tumor, demonstrating intramural distribution of the punctuate shape calcifications with acoustic shadows ( $A \& B$ ). sm: submucosa; mp: muscularis propria; black arrows: calcifications in the $\mathrm{sm}$ layer; white arrow: calcification in the muscularis propria.

\section{References}

1. Nishimura $K$, Togashi $K$, Tohdo $G$, et al.: Computed tomography of calcified gastric carcinoma. J Comput Assist Tomogr 1984; 8: 1010-1011.

2. Wise $A G$, Sage MR: Computed tomography of calcified gastric carcinoma: a case report. Australas Radiol 1987; 31: 267-268.

3. Hwang HY, Choi BI, Han JK, et al.: Calcified gastric carcinoma: CT findings. Gastrointest Radiol 1992; 17: 311-315.

4. Rösch T, Classen $M$ : Normal endosonographic findings and variations. In: Rösch T, Classen M (eds): Gastroenterologic endosonography. Thieme, Stuttgart 1992; 36-44.

5. Aibe T, Fuji T, Okita K, et al.: A fundamental study of normal layer structure of the gastrointestinal wall visualized by endoscopic ultrasonography. Scand J Gastroenterol 1986; 21 (Suppl. 123): 6-15.

Y. Songür, T. Okai, H. Watanabe, T. Fujii, Y. Motoo, A. Ooi, N. Sawabu

Department of Internal Medicine and Pathology, Cancer Research Institute, Kanazawa University, Kanazawa, Japan

Corresponding Author

Takashi Okai, M.D.

Department of Internal Medicine

Cancer Research Institute

Kanazawa University

4-86 Yoneizumi, Kanazawa 92

Japan

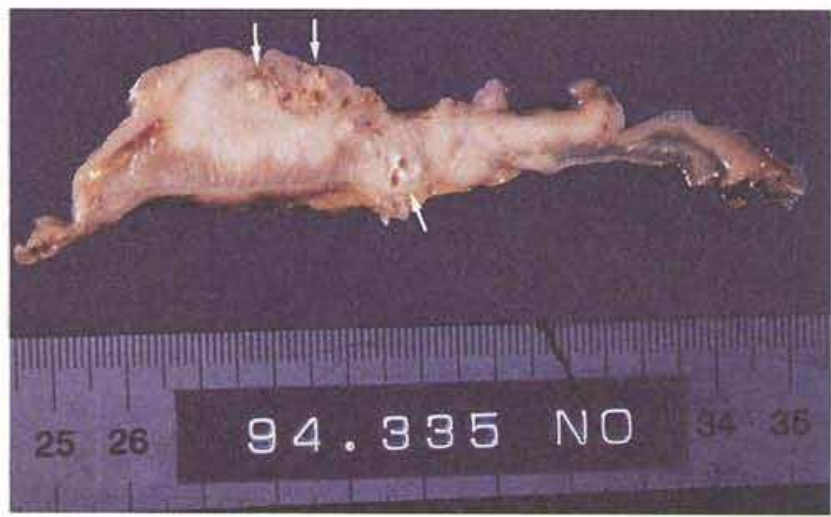

Figure 2a: Cut surface of the resected specimen corresponding to the presence of calcifications (arrows).

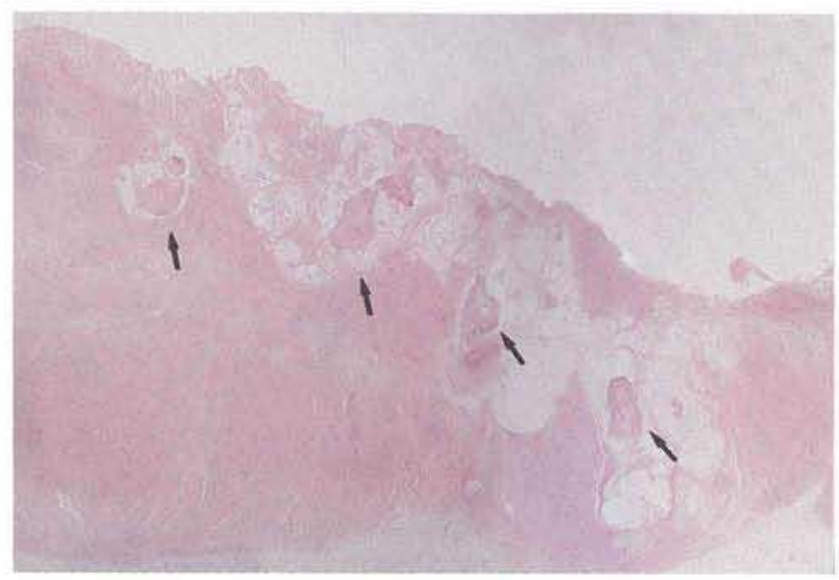

Figure $\mathbf{2} \mathbf{b}$ : Histologic features of the tumor showing extensive areas of mucin pools with scattered calcifications (arrows). $H \& E, \times 5$. 